\title{
Ethical issues related to research on pregnant school-going teenagers in South Africa
}

\section{Sogo France Matlala}

\author{
Department of Public Health \\ University of Limpopo, Polokwane, South Africa \\ France.Matlala@ul.ac.za
}

\begin{abstract}
Background: This paper describes the procedures the researcher followed in order to both observe and respect ethical issues when conducting research on pregnant teenagers attending secondary schools in South Africa.

Data sources and methods: The paper draws on the literature to discuss pregnant school-attending teenagers as a vulnerable population and indicates the measures the author took to respect ethical issues.

Findings: Pregnant school-going teenagers in South Africa are vulnerable as they are young, pregnant and under the authority of a school. Pregnancy amongst school-going teenagers is a public health issue that requires research in order to yield solutions and pregnant teenagers are important participants in such research as they have experiences and suggestions to share.

Conclusion: Researchers should ensure that pregnant teenagers are given sufficient information about the research process so they can give informed voluntary consent to participate. Furthermore there should be justice, confidentiality, anonymity and beneficence throughout the research process
\end{abstract}

Key words: Teenage pregnancy; informed voluntary consent; vulnerable population; research ethics; learner pregnancy

\section{Introduction}

Pregnancy amongst school-going teenagers is recognised as an important public health issue due to the link between teenage pregnancy, school dropout, educational attainment and health (Johnson et al. 2016; Karabo \& Ayiga 2014). As such, it is important to conduct research on pregnancy amongst learners. Pregnant school-going teenagers are a vulnerable population due to their age, the fact that they are pregnant and the fact that they are under the authority of a school. Therefore, researchers who conduct research on pregnant school-going teenagers should ensure that the ethical principles of respect for persons, beneficence and justice are observed (Schwenzer 2008). Lindsjö (20/2) indicates that ethical issues are based on the notion of what researchers should and should not do while conducting research or writing research findings.

This paper discusses the ethical issues related to research undertaken on pregnant school-going teenagers as a vulnerable population that the author faced while conducting a $\mathrm{PhD}$ study on social support for pregnant learners in South Africa. In this paper the author discusses some of the complex ethical issues that arose in accessing and interviewing this vulnerable population in South Africa. Some of the complex issues included the need to be mindful of topic sensitivity, the vulnerability of participants, the informed consent process, and the potential impact of the research on the emotions of the participants.

\section{Pregnant school-going teenagers as a vulnerable population}

Vulnerability in research refers to situations where target populations may be at an increased risk of physical or psychological harm because of the unequal power status between participants and researchers which leads to diminished ability on the part of the participants to protect themselves. Examples of vulnerable populations in research include children, schoolchildren, prisoners and pregnant women (Department of Health Republic of South Africa 2015; Bernard 2013; Campbell-Crofts et al. 2013; Lindsjö 20I2; Schwenzer 2008). In South Africa, pregnant school-going teenagers who are under the age of 18 years are classified as children or minors with limited competence to give informed consent to participate in research as they may lack the intellectual maturity to understand research procedures or may not have the power to refuse to participate (Department of Health Republic of South Africa 2015; Bernard 2013; Johnson et al. 2016; South 
Africa 2005; Sutton et al. 2003). However, Bernard (20I3) argues that, for the purposes of research, teenagers should not be considered as children as there is evidence to show that teenagers aged 14 and above are able to make sound decisions. Pregnant school-going teenagers are considered a vulnerable population as they are subjected to the authority of the school while pregnant and because of potential risks to their unborn children (Vreeman et al. 2012; Schwenzer 2008). Being a learner at a school causes learners to be vulnerable to feelings of being under pressure to participate in research that teachers approved of, as the learners are under the authority of the school (Schwenzer 2008). In South Africa, the Department of Health has clear guidelines for the protection of vulnerable groups when they are asked to take part in research (Department of Health Republic of South Africa 20I5; van Wijk \& Harrison 2013). Campbell-Crofts et al. (20I3) point out that the purpose of identifying vulnerable populations in research is not to exclude them from participating but to ensure that full consideration is given to allow their maximum participation within the requirements of ethical research. van Wijk \& Harrison (2013) suggest that researchers should take action to avoid accidental reinforcement of stigmas affecting certain research populations, exploitation of vulnerable participants and the causing of distress to people who have already suffered traumatic events.

\section{Ethical principles}

Sherlock \& Thynne $(2010)$ indicate that, in research, ethics refers to moral reflection, choice and accountability by researcher during the research process. A fundamental principle of ethical research is to protect the rights of participants by putting in place measures to protect the participants and to prevent violation of their rights. To achieve this, researchers should observe and respect the dignity of participants by obtaining their informed, voluntary consent to participate, to strive to do good to participants, while protecting them from harm, to do justice when recruiting participants and to be suitably qualified to conduct research (Campbell-Crofts et al. 2013).

\section{Informed voluntary consent to participate}

According to Lindsjö (20I2) informed consent means that researchers should explain to the participants what it is that they plan to do and what the intended outcomes are before they can begin to carry out the research. According to Campbell-Crofts et al. (20l3) researchers should recognise the personal dignity and autonomy of participants in their decision-making process regarding their participation and this should include the right of participants to full disclosure of the research procedure, potential risks and the benefits of participation. In this study of pregnant school-going teenagers in South Africa, the researcher obtained informed consent from the parents for their pregnant school-going daughters to take part in the study voluntarily and obtained consent from the pregnant teenagers themselves. Parents were asked to give consent to their pregnant daughters' participation in the study as their pregnant daughters were not legally competent to give consent on their own (Strode et al. 2010; Strode \& Slack 20I I). To obtain informed consent, both parents and their pregnant daughters were fully informed about the process of the research, the research problem, the purpose and objectives of the study and the benefits of participation therein. They were allowed to ask questions for clarification when they did not understand or needed more information. Children's participation in research requires the consent of a parent or guardian but Johnson et al. (2016) point out that this might be a problem when the study is about children whose behaviours are not approved of by parents, such as being pregnant while still attending school.

Informed voluntary consent to participate in research also includes the right of participants to withdraw their participation without penalty (Polit \& Beck 20I2). In this study the researcher explained to the pregnant school-going teenagers that they were free to withdraw from participation even after they had agreed to participate and that they would not be penalised for withdrawing. Sherlock \& Thynne (2010) indicate that informed consent to participate in research should be seen as an on-going process, which includes the right of participants to withdraw from participation at any stage of the research process.

\section{Privacy, confidentiality and anonymity}

In this study the researcher ensured the privacy and confidentiality of the information shared by the pregnant school-going teenagers by conducting the semi-structured interviews in a private office at the schools and by keeping the transcripts in a locked place, accessible to the researcher alone. The right to privacy of the pregnant school-going teenagers was maintained throughout the study by asking only questions relevant to the aims and objectives of the study. Polit \& Beck (20/2) indicate that researchers should ensure that their research is not more intrusive than it needs to be and that the participants' privacy is maintained throughout the study. To further ensure privacy, the researcher informed participants not to mention their names, their schools' names or the names of any other person 
during the interviews so that data collected could not as suggested by de Vos et al. (20l I). To maintain confidentiality, the researcher entered into a confidentiality agreement with an independent coder who coded the data during analysis (A copy is attached as Figure I: Confidentiality Agreement). Confidentiality is important for protecting the identities of, and information provided by, research participants. Pittaway et al. (20l0) indicate that researchers should protect the identities of participants as inappropriate disclosure of identities be linked to the identities of participants in any way, my cause unintended harm to participants. When research involves sensitive topics, such as falling pregnant while still attending school and attempting to conceal it, informed consent should include an assurance of anonymity. If confidentiality and anonymity are not guaranteed, some participants may refuse to participate in the research and some of those who participate may adjust their responses to protect their identities (Lindsjö 20I2).

\section{Confidentiality Agreement for Independent Coder}

Research title: A model to facilitate social support to pregnant learners attending secondary in South Africa

- I understand that all the material I am asked to code is confidential

- I understand that the contents can only be discussed with the researcher.

- I will not keep any copies of the information nor allow third parties to access them.

- I will delete all transcripts and other relevant files from my computer after coding.

Independent Coder's signature:

Independent Coder's name:

Date:

Researcher's signature:

Researcher's name:

Date:

The Independent Coder will be given a copy of this form to retain for his/her records

Figure I Confidentiality Agreement

\section{Principle of beneficence}

Campbell-Crofts et al. (2013) indicate that in ethically acceptable research, the potential benefits of the findings should be greater than any risks to the participants involved. Polit \& Beck (20I2) add that the principle of beneficence imposes a duty on researchers to minimise harm and to maximise benefits to participants. In this study the researcher indicated in the consent letter to both the parents and their pregnant daughters that there were no risks involved in participating in the study. Indeed, during the interviews, there were no signs of psychological trauma or distress experienced by the pregnant school-going teenagers that would have required referral to a debriefing session by a counsellor for support. However, the researcher had a counsellor available if debriefing of the pregnant school-going teenagers became necessary. The benefit of participation is the sharing of experiences about the health of pregnant school-going teenagers and giving input to guidelines developed to facilitate social support for pregnant school-going teenagers attending secondary schools in South Africa. Campbell-Crofts et al. (20/3) indicate that there is a risk of distress and anxiety from the disclosure of personal information which may be stigmatising, embarrassing or socially unacceptable in qualitative interviews. These risks may be in the form of psychological harm, such as feelings of worthlessness, guilt, anger, fear, embarrassment, humiliation, distress and an increase in anxiety levels, resulting in episodes of crying, as a result of participation in the interview process. Qualitative researchers should have measures in place to meet the emotional needs of the participants, in the form of experienced counsellors to assist participants and their families. Pittaway et al. (2010) indicate that the ethical challenge for researchers is to add something of value to the lives of people taking part in research, recognising them as participants and beneficiaries in the process and not simply as subjects or sources of 
data. According to Lindsjö (20/2) 'do no harm to research participants' means that participation must not put at risk the psychological health of participants, or put them at risk of stigmatisation or any form of punishment by the family or community. Researchers should move from simply being concerned about not doing harm to the participants, to being socially responsible by bringing improvements to the lives of participants. Lindsjö (20I2) further indicates that participating in research can make the voices of marginalised or vulnerable people heard in a larger context. A further benefit of participating in research is the fact that research findings may influence or contribute to policy development. Researchers can raise the self-esteem of their participants, making vulnerable participants feel valuable by informing them and showing them that their information is valuable. Furthermore, qualitative phenomenological interviews can sometimes have a therapeutic value as they provide participants with opportunities to give voice to their own stories and acknowledge the validity of their own experiences as ways of making sense of past experiences when they to talk about experiences that are traumatic and sometimes stigmatising. Bernard (2013) refers to encouraging vulnerable participants to understand that they have something valuable to say about their experiences as 'coming to voice' and 'naming your reality'. Bernard (2013) further indicates that building rapport with vulnerable participants may lead to an increase in their selfconfidence, personal development and social skills. Research on vulnerable populations shows that some of the participants regard participation in research as a positive experience which enables them to tell their stories. Furthermore, participants feel that, by taking part in the research, their stories may benefit other people (Sherlock \& Thynne 2010). However, it is important to acknowledge that some vulnerable participants may experience distress when talking about their painful past experiences and, as such, it important to try to balance the risk of participation with the potential benefits to participants and the wider community (Bwakura-Dangarembizi et al 2012; Sherlock \& Thynne 2010).

\section{Principle of justice}

The principle of justice implies fairness and equity, which relates to the participants' right to fair treatment and their right to privacy (Polit \& Beck 20I2). In this study on social support for pregnant learners in South Africa, the researcher ensured that pregnant school-going teenagers, as vulnerable persons, were not targeted to participate in the study for the convenience of the researcher, but to contribute to a public health benefit. The researcher targeted both rural and urban secondary schools to ensure that all pregnant school-going teenagers meeting the criteria for inclusion were given a chance to participate and to benefit from participation. Campbell-Crofts et al. (20l3) indicate that respecting the principle of social justice involves concern for fairness and equity towards the participants, including people who may be remotely affected by the research during the recruitment phase, regarding the risks and benefits of the research.

\section{Scientific integrity of the researcher}

de Vos et al. (20lI) state that researchers have an obligation to the discipline of science in the way they conduct research and report their findings. The researcher in this study submitted the research proposal to, and obtained ethical clearance from, a university higher degrees research and ethics committee (HDREC) and permission from the Department of Basic Education was obtained before starting with data collection. It is a requirement in South Africa that research proposals for PhD studies be approved by the research ethics committee of the university under which the studies are registered. As Campbell-Crofts et al. (2013), Sherlock \& Thynne (20I0) and Bwakura-Dangarembizi et al. (20I2) point out, the role of university higher degrees and ethics committees is to review research proposals, where they evaluate the integrity of the research design and the protection of the health and rights of participants. To further maintain scientific integrity, the researcher followed guidelines for conducting qualitative and theory generating research (Chinn \& Kramer 20II; Liamputtong 2013). A semi-structured phenomenological interview was used to collect data and an audio recorder was used, with permission from the participants, to record the interviews. Data was analysed using Tesch's open coding process as described in Matlala et al. (20/4) and Matlala et al. (2015). Trustworthiness of the study was achieved by ensuring credibility, dependability, transferability and confirmability, as described in Matlala et al. (20|4). Besides, the researcher is a professional nurse and observed the ethical principles prescribed by the nursing profession in South Africa (South African Nursing Council 2013). According to Polit \& Beck (20/2), in a qualitative research approach, researchers are data collecting instruments and also create the analysis process and, as such, they have to establish confidence in the findings by indicating their relevant experience and qualifications. The researcher is qualified in nursing, psychology and education and has some experience in conducting and supervising research. Campbell-Crofts et al. (2013) point out that nursing as a profession is required to protect health, therefore nurses who 
conduct research should critically analyse their research methods so that their research is carried out in an ethical manner that upholds and promotes scientific rigour while protecting vulnerable populations. Researchers with integrity will temporarily suspended interviews if any participant becomes uncomfortable, fatigued or distressed and may even allow the participant to withdraw permanently from the study, as Campbell-Crofts et al. (2013) suggest. Researchers should publicise research findings, both positive and negative, to allow for examination of the research by experts in the field.

\section{Conclusion}

Pregnant school-going teenagers should be allowed to participate in research by sharing their experiences but, due to their age, the fact that they are pregnant and the fact that they are under the authority of a school, they are vulnerable to being coerced to participate against their will. Researchers should therefore apply the ethical principles of informed consent, justice, beneficence, confidentiality and scientific integrity to protect the participants. Conducting research ethically will yield findings which will assist the country with solutions to address the challenge of supporting pregnant teenagers who choose to continue attending school. Ethics review committees, parents and schools should work together to enable researchers to access pregnant school-going teenagers, while at the same time protecting these teenagers against participation under coercion.

\section{References}

Bernard, C 2013. Ethical Issues in Researching Black Teenage Mothers with Harmful Childhood Histories: Marginal Voices. Ethics and Social Welfare 7,(I):54-73, DOI: I 0.1080/I 7496535.20| 2.666754.

Bwakura-Dangarembizi, M., Musesengwa, R., Nathoo, K. J., Takaidza., P., Muhte, T \& Vhembo, T 20/2. Ethical and legal constraints to children's participation in research in Zimbabwe: Experiences from the multicenter pediatric HIV ARROW trial. BMC Medical Ethics I3, (I), I 7.

Campbell-Crofts, S., Field, J \& Fetherstonhaugh, D 2013. Ethical considerations for nurses undertaking research with a potentially vulnerable population with chronic kidney disease. Renal Society of Australasia Journal 9, (2):74-79.

Chinn, P. L \& Kramer, M. K 20I I. Integrated theory and knowledge development in nursing. 8th ed. ST. Louis: Elsevier Mosby.

de Vos, A.S., Strydom, H., Fouche., C.B \& Delport, C.S.L 20II. Research at grass roots for social science and human service profession. $4^{\text {th }}$ ed. Van Schaik: South Africa.

Department of Health Republic of South Africa 2015. Ethics in Health Research: Principles, Processes and Structures. $2^{\text {nd }}$ ed. Pretoria: Government Printers.

Johnson, K. E., Morris, M., Rew, L \& Simonton, A. J. 2016. A Systematic Review of Consent Procedures, Participation Rates, and Main Findings of Health-Related Research in Alternative High Schools From 2010 to 2015. The Journal of School Nursing, 32,(I): 20-3I.

Karabo, M \& Ayiga, N 20I4. Rates and predictors of school pregnancy among black women in the North West province, South Africa. African Population Studies 28, ( I):636-647.

Liamputtong, P 2013. Qualitative research methods. 4th ed. Victoria: Oxford University Press.

Lindsjö, K 2012. Research in a development setting: Ethical concerns during fieldwork in Tanzania. In $\mathrm{K}$, Jacobsson \& K, Sjöberg (eds.). Pondering on methods: A variety of methodological concerns. Sweden: Lund University pp. 95-106.

Matlala, S.F., Nolte, A. G. W \& Temane, M. A 2014. Secondary school teachers' experiences of teaching pregnant learners in Limpopo province, South Africa. South African Journal of Education 34, (4): Art. \# 1027, 12 pages, http://www.sajournalofeducation.co.za

Matlala, S., Nel, E \& Chabeli, M 20I5. Confidentiality protection in consulting with modern medicine following use of traditional medicine: perspectives of South African clients. Journal of Psychology in Africa 25, (3): 195-200.

Pittaway, E., Bartolomei, L. \& Hugman, R 2010. "Stop Stealing Our Stories": The Ethics of Research with Vulnerable Groups'. Journal of Human Rights Practice 2,(2): 229-25I.

Polit, D. F \& Beck, C. T 20I2. Nursing research. Generating and assessing evidence for nursing practice. 8th ed. Philadelphia: Lippincott Williams and Wilkins.

South Africa 2005. Children's Act 38 of 2005. Pretoria: Government Printers

South African Nursing Council 2013. Code of ethics for nursing practitioners in South Africa. Pretoria: South African Nursing Council.

Schwenzer, K. J 2008. Protecting Vulnerable Subjects in Clinical Research: Children, Pregnant Women, Prisoners, and Employees. Respiratory Care 53, (I0): I 342-I349.

Sherlock, C \& Thynne, C. 2010. Research with Vulnerable Groups: Collaboration as an Ethical Response. Journal of Social Work Values and Ethics, 7(2) 
Strode, A., Slack, C and Essack, Z 20I0.Child consent in South African law: Implications for researchers, service providers and policy-makers. South African Medical Journal, 100(4):247.

research in South Africa. South African Journal of Bioethics and Law 4, (2):69-73.

Sutton. L. B., Erlen,. J. A., Glad, J. M \& Siminoff, L. A 2003. Recruiting vulnerable populations for research: Revisiting the ethical issues. Journal of Professional Nursing 19, (2): 106-I I 2

van Wijk, E \& Harrison, T 20I3. Managing Ethical Problems in Qualitative Research Involving Vulnerable Populations, Using a Pilot Study.
Strode, E, A and Slack, C. M 20I I. Using the concept of 'parental responsibilities and rights' to identify adults able to provide proxy consent to child

International Journal of Qualitative Methods 12:570-586.

Vreeman, R., Kamaara, E., Kamanda, A., Ayuku, D., Nyandiko, W., Atwoli, L., Ayaya, S., Gisore, P., Scanlon, M \& Braitstein, P 2012. Community Perspectives on Research Consent Involving Vulnerable Children in Western Kenya. Journal of Empirical Research on Human Research Ethics 7, (4): 44-55. Doi: I0.1525/jer.2012.7.4.44. 